\title{
The activation of unrelated and canceled intentions
}

\author{
RICHARD L. MARSH, JASON L. HICKS, and ERIC S. BRYAN \\ University of Georgia, Athens, Georgia
}

\begin{abstract}
The intention superiority effect is the finding that intentions to perform an activity are stored in a heightened state of activation. The effect has also been generalized to the finding that once an intention is fulfilled, it is inhibited relative to more neutral material about which no intentionality has been formed. In two experiments, we tested some ecological and naturally occurring situations taken from the literature on prospective memory and demonstrated that they have consistent consequences for the activation level of an intention. In Experiment 1, a constellation of unrelated activities displayed heightened activation prior to completion and displayed inhibition after completion. In Experiment 2, canceling the intention resulted in inhibition just as completing the intention does in this paradigm. The results are discussed in terms of their practical and theoretical importance to theories of prospective memory.
\end{abstract}

The term prospective memory is a deceivingly simple label that refers to a broad class of cognitive tasks that share one obvious feature. This feature is that people establish an intention in memory to perform some action in the future. Therefore, the cognitive tasks that fall under the rubric of prospective memory will be as diverse and varied as both the types of intentions that people establish for themselves and the conditions under which those intentions can be fulfilled. For example, the intention to deliver a message to a friend or colleague when they are next encountered has been labeled an event-based prospective memory task (see, e.g., Einstein \& McDaniel, 1990; Einstein, McDaniel, Richardson, Guynn, \& Cunfer, 1995; McDaniel \& Einstein, 1993). The intentions to attend a colloquium or to remove dinner from the oven at a specific time have been labeled time-based prospective memory tasks (e.g., Einstein \& McDaniel, 1990). Distinctions such as these are quite useful insofar as they serve to partition the space of prospective memory tasks. Although many other distinctions exist, it should be clear from just these two that the underlying cognitive processes that support making an event-based task (e.g., Einstein \& McDaniel, 1996) are likely to be very different from those that involve the time-monitoring behavior in a timebased task (e.g., Harris \& Wilkins, 1982; Wilkins \& Baddeley, 1978). Similarly, so too would the cognitive processing be different in completing intentions that have been labeled steps that can be successfully completed within a window of time versus those labeled pulses that must be completed at a specific time (e.g., Ellis, 1988).

As small-scale theories emerge that identify the cognitive processes that support each of these various prospec-

E.S.B. served as the experimenter. J.L.H. is now at Louisiana State University. Correspondence concerning this article should be addressed to R. L. Marsh, Department of Psychology, University of Georgia, Athens, GA 30602-3013 (e-mail: marsh@meme.psy.uga.edu). tive remembering tasks, the next step will be to determine where the theories of each prospective task share overlapping cognitive components and mechanisms. Although this step is unlikely to occur in the immediate future, the interim approach that we have taken in this article is to identify and to investigate one obvious common thread that runs through all prospective memory tasks: the intention itself. Although different intentions are likely to vary in features such as their complexity (Mäntylä, 1993, 1996), importance (Kvavilashvili, 1987), or the social demand characteristics surrounding completion of the intention (Meacham, 1988), all intentions do share the feature that they were stored in memory at some point; otherwise the "intention" would constitute nothing more than a fleeting thought, or merely a wish or a desire.

Recently, Goschke and Kuhl (1993) reported a series of four experiments whose results suggested that intentions (i.e., prospective memories) reside in memory with a heightened state of activation. In their paradigm, participants learned a pair of scripts such as clearing a messy desk and setting a table for dinner. Each script was composed of five related actions of the form verb the noun (e.g., distribute the cutlery for setting a table). After learning a pair of scripts to criterion, people were told which of the two scripts they would have to perform later. Presumably, these instructions turned one script of the pair into a prospective script and one into a neutral script. In an immediate recognition test that followed the prospective instruction, response latencies were faster to items from the prospective script than to items from the neutral script. Thus, Goschke and Kuhl (1993) concluded that some intentions have privileged status in memory, and accordingly, they dubbed their findings the intention superiority effect.

Not all intentions, however, have such privileged status in memory. Goschke and Kuhl (1993) also had people learn pairs of scripts, after which they were told that they 
would have to watch the experimenter perform one of the two scripts. The prospective intention to watch did not result in faster recognition latencies for the prospective script than for the neutral script in a pair. Therefore, Goschke and Kuhl (1993) concluded that only intentions to fulfill a self-performed action as compared with intentions that do not involve action reside in memory with privileged status. ${ }^{1}$ In our own work on the intention superiority effect, we have explored the consequences of completing the action before its availability in memory is assessed (Marsh, Hicks, \& Bink, 1998). In other words, we investigated both the level of activation prior to script enactment as well as the "fate" of heightened activation after an intention had been completed. We predicted that a completed intention might be inhibited, thereby losing its privileged status in memory. Using a lexical decision task rather than recognition latency, we found evidence that uncompleted and partially completed activities were more available in memory (i.e., shorter lexical decision times) whereas completed intentions were less available (i.e., longer lexical decision times). For a given pair of scripts, both of these comparisons were made relative to the neutral script with which the prospective script was paired. This point is important, because the neutral member of the pair has no intentionality associated with it. Therefore, when a prospective script has not yet been completed, it will appear more activated (faster latencies) than the neutral script, which will, as a consequence, appear inhibited (slower latencies). The converse will be true after the prospective script has been performed. The activation of an uncompleted script also represents inhibition of the neutral script with which it was paired (see Marsh, Hicks, \& Bink, 1998).

In the present experiments, our goal was to use the intention superiority paradigm to explore somewhat more "ecologically valid" manipulations of prospective remembering. We place this phrase in quotes to highlight the fact that our manipulations were intended to mirror realworld differences in prospective memory situations that were empirically tested in the laboratory. Prospective memory is, after all, a form of memory that we use every day (see, e.g., Marsh, Hicks, \& Landau, 1998). However, the scripts that have been used to study the intention superiority effect consist of five or six highly semantically related actions (e.g., measure the grounds and pour the water for a script about brewing coffee). Our intuition was that actions such as these correspond to real-world situations in which people have constellations of related prospective memories that they intend to accomplish on a more or less regular basis. For example, the related intentions of doing laundry, washing dishes, vacuuming, and so forth might correspond to a set of intentions concerning cleaning one's abode. In contrast, our belief was that in everyday life people often also have constellations of prospective memories that are not as highly semantically related to one another. For example, the intentions to buy milk, stop by the bank, and pick up dry cleaning might constitute several (semantically) unrelated activities that one intends to perform on the way home from work.

The basic question that we address in Experiment 1 is whether the intention superiority effect can be found with constellations of unrelated activities just as it has been demonstrated with scripts of related activities. The scripts that have been tested thus far constitute a sequence of actions related to a single goal such as brewing coffee. However, people do establish intentions to do several unrelated activities and group them together under looser goals such as things to do on the way home, as in the preceding example. We believe that these unrelated intentions should show the heightened activation preceding completion and the inhibition following completion just as the semantically related actions did in our earlier work (Marsh, Hicks, \& Bink, 1998). It is possible, however, that semantically unrelated activities do not give rise to an intention superiority effect, or perhaps that they give rise to an attenuated effect. Marsh, Hicks, and Bink found that the heightened activation and inhibition effects were on the order of 20-30 msec in a lexical decision task. Therefore, some attenuation could be observed.

Experiment 2 is an extension of the intention superiority paradigm based on results obtained by Marsh, Hicks, and Landau (1998) in a naturalistic (i.e., everyday) examination of prospective memory. In those experiments, we asked people to write down their plans for the upcoming week and had them return a week later to document what they had completed and what they had not. For the intentions that went unfulfilled, we asked for a reason why they had not yet been completed. Surprisingly, only a small percentage of intentions were overtly forgotten. The vast majority were either consciously displaced by other activities and therefore postponed or were canceled by factors that both were and were not under the person's control. Although we could not devise a way to make participants overtly forget the intention that is established in the intention superiority paradigm, we could cancel the intention after it had been established. Doing so mimics the real-world situation in which intentions become impossible to complete through overt cancellation on the part of another (e.g., a colleague who has temporarily forgotten she was to teach a class must cancel a lunch date) or on the part of one's self (e.g., deciding that one does not have the time or money to participate in a planned event). The predictions for the fate of the activation of a canceled intention are unclear. On the one hand, the activation level may subside or even show the inhibition effect of a completed intention because it is no longer a prospective memory. On the other hand, the heightened activation level in memory may persist because the intention has gone unfulfilled, much as when uncompleted tasks are remembered better in the Zeigarnik effect (see Butterfield, 1964, and Marsh, Hicks, \& Bink, 1998, Experiment 4). We believe that postponed intentions should display heightened activation, whereas canceled intentions (like those tested in Experiment 2) 
would display inhibition. ${ }^{2}$ We turn now to the details of the two experiments.

\section{EXPERIMENT 1}

Our goal in this experiment was to determine whether a constellation of unrelated activities that were going to be performed during the same time period would possess heightened activation prior to completion and become inhibited after completion. We have obtained this exact pattern of results with scripts composed of related activities (Marsh, Hicks, \& Bink, 1998, Experiment 3). To mimic the real-world conditions in which people establish several unrelated intentions to be accomplished in the same time period, we scrambled the scripts that we had used previously (and added several unrelated actions) in order to create pairs of scripts in which each script comprised entirely unrelated activities (an example is provided).

\section{Method}

Participants. Forty University of Georgia undergraduates volunteered in exchange for partial credit toward a course research requirement. Each participant was tested individually in sessions that lasted approximately $45 \mathrm{~min}$. Four participants who had difficulty remembering the order in which to perform the components of the scripts or forgot which script to perform were replaced.

Materials. The four scripts used by Marsh, Hicks, and Bink (1998), each of which contained five actions, constituted the basic materials. One component action from each of the four scripts was randomly assigned to each of four new sets of actions from our earlier materials. We labeled these consecutively as Set One, Set Two, and so forth. Thus, each set had four actions from our original materials. A fifth, semantically unrelated action was added from some stimulus materials that we had on hand from an experiment on subject performed tasks. By way of example, the Set Two script contained the following unrelated actions: Distribute the cutlery, Sharpen the pencil, Pour the water, Spray the aerosol, Stack the articles. For the lexical decision tasks, the nouns and verbs from the sets of actions were combined with an equal number of valid English nonscript words; and nonwords were added in equal numbers to all of the valid words. More specifically, in each of two lexical decision tasks that tested a given pair of scripts that were learned together, there were 20 script items, 20 nonscript words, and 40 nonwords. In each lexical decision task, 12 items for practice ( 6 words and 6 nonwords) preceded the critical items. Therefore, the probability of saying "yes" and "no" in the lexical decision tasks was $50 \%$. Each of the nonscript words was matched to the script items to control for word frequency and syllabic length. Nonwords were pronounceable and were matched to script and nonscript words for syllabic length. Complete randomization of the lexical decision items for each participant was under software control.

Procedure. The procedure was identical to that used by Marsh, Hicks, and Bink (1998) in their Experiment 3. Participants were told that they would have to learn two sets of actions in two separate blocks of the experiment. They were also told that after learning a pair of scripts they would be told which one of the pair they would have to perform. The instruction therefore made one script a prospective script and the other a neutral script. Participants were told that they would have to perform a counting backward task and lexical decision tasks. Detailed instructions on both tasks were given at the start of the experiment before the first pair of scripts had been learned. After learning a pair of scripts, participants either performed one of the scripts that they had just learned and then took a lexical decision task (to measure activation post-completion), or they performed the lexical decision task and then completed the five unrelated actions constituting the prospective script (to measure activation prior to completion). In this fashion, we obtained measurements of the availability of script items both prior to and after completion of the intended activities. Complete counterbalancing ensured that each script was rotated through first and second blocks, as well as served as the prospective versus neutral script, in addition to being tested in the lexical decision task prior to versus after completion of the script.

As in our earlier study, participants were shown each set of actions twice for initial learning. The title (e.g., Set Two) was shown for $10 \mathrm{sec}$, followed by the consecutive addition of a component action every $10 \mathrm{sec}$. Once a component action appeared on the screen, it remained there. This procedure meant that the script title had been on the screen for $60 \mathrm{sec}$ after the fifth action was presented. The entire script remained on the screen for an additional $30 \mathrm{sec}$ (i.e., a total of $1 \mathrm{~min} 30 \mathrm{sec}$ ). This procedure was repeated for the second script in a pair. Then the two scripts were presented again in an identical fashion for a second learning trial (for a total learning time of $6 \mathrm{~min}$ ). Participants were required to recall the scripts by writing them down on paper. If learning was not perfect, the two scripts were presented again once and recall was reassessed. Participants cycled through this procedure until both scripts could be recalled perfectly. Immediately after successful script recall, a three-digit number was presented on the screen and participants had to count backward by threes from that number for $45 \mathrm{sec}$ as a buffer clearing task. After counting backward, the computer beeped and participants were informed which of the two sets of actions they would perform. The instructions appeared on the screen for $3 \mathrm{sec}$ and the prospective script title was preceded by "You will perform:" whereas the neutral script title was preceded by the instruction "You will not perform:" Participants were either immediately engaged in the lexical decision task and then completed the script (to assess activation prior to script completion) or were led from the workstation to perform the script and then led back to the workstation to complete the lexical decision task (to assess activation after script completion). The materials for the scripts had been laid out on tables behind the workstation. If participants performed the lexical decision task prior to script completion in the first block of the experiment, they performed it after script completion in the second block, or vice versa. The administration of the lexical decision task prior to or after completion was counterbalanced across the two blocks of the experiment so that aggregate results would not reflect any practice effects or other artifactual influences. Thus, the assessment of activation prior to or after script completion was manipulated as a within-subjects variable. These procedures were identical to those which we had used before (see Marsh, Hicks, \& Bink, 1998, Experiment 3)

\section{Results and Discussion}

Unless noted otherwise, the probability of a Type I error does not exceed $5 \%$ in any statistical analysis in this article. When specific contrasts are reported, the error term reflects the data from the conditions of interest. In this experiment and the next one, trials reflecting lexical decision errors or latencies beyond 2.5 standard deviations from a participant's mean performance for a specific condition of interest were excluded from the analyses. Thus, we trimmed not only on a participant basis (as we did in our earlier study), but the trimming conservatively occurred individually within the four basic conditions of interest (see Ratcliff, 1993, for details). In this experiment, $3.4 \%$ were error trials and $1.0 \%$ were identified as outliers by the trimming process. 
Table 1

Overall Response Latency (in Milliseconds) to Script, Nonscript, and Nonwords in the Lexical Decision Tasks for Experiments 1 and 2

\begin{tabular}{crrr} 
& \multicolumn{3}{c}{ Item Class } \\
\cline { 2 - 4 } & Script & Nonscript & Nonwords \\
\hline Experiment 1 & & & \\
$M$ & 564.3 & 620.4 & 670.4 \\
$S E$ & 10.1 & 11.1 & 10.6 \\
Experiment 2 & & & \\
$M$ & 551.3 & 617.0 & 676.7 \\
$S E$ & 11.4 & 15.1 & 14.8 \\
\hline
\end{tabular}

Pooling over the two lexical decision tasks, the first two rows of Table 1 set forth the overall latencies to the three classes of items tested. An orderly pattern of activation was found in which script items were responded to most quickly, followed by nonscript words; responses to nonwords were slowest. In a within-subjects one factor analysis of variance (ANOVA) with the three levels specifying the three classes of items, these latencies differed significantly $\left[F(2,78)=193.93, M S_{\mathrm{e}}=581.08\right]$. Simple contrasts identified that nonscript words were responded to more slowly than script words $[t(39)=15.30]$, but responses to these nonscript words were faster than those to the nonwords $[t(39)=7.93]$. Applying the interpretation that faster latencies reflect more activation in memory (e.g., Ratcliff \& McKoon, 1978), script words possessed the most activation because they had been studied previously during the learning phase of the experiment.

Among only the script items, latency differed as a function of whether the script was prospective or neutral. More important, latency differed as a function of whether the prospective script had been completed prior to or after the assessment of activation. The data from the script items are set forth in Figure 1. In a $2 \times 2$ within-subjects ANOVA with the factors of type of script (prospective vs. neutral) and placement of the lexical decision task (prior to or after completing the intention), neither the main effect of script type $\left[F(1,39)<1, M S_{\mathrm{e}}=1,222.68\right]$ nor the main effect of when the lexical decision task was administered $\left[F(1,39)=1.65, M S_{\mathrm{e}}=1,598.46\right]$ was statistically significant. However, the crossover interaction observed in Figure 1 was $\left[F(1,39)=8.59, M S_{\mathrm{e}}=1,174.17\right]$. These results replicate Marsh, Hicks, and Bink's (1998) finding that, prior to completion a script, the components related to the intention appear to have a heightened level of activation relative to more neutral material about which no intentionality had been formed. In addition, the results also replicated our earlier finding that, once completed, the contents of the intention become somewhat inhibited relative to more neutral material. Thus, a constellation of unrelated activities gives rise to the same patterns of activation pre- and post-completion that have been found with highly related materials.

In terms of specific contrasts, the inhibition associated with completed scripts in comparison with the neutral scripts with which they were paired was statistically sig- nificant $[t(39)=2.2]$. The heightened activation associated with as yet uncompleted scripts was only marginally significant by a conservative two-tailed convention $[t(39)=1.89, p=.06]$. However, in our favor, the heightened activation associated with to-be-performed intentions has been replicated six times across the Marsh, Hicks, and Bink (1998) and Goschke and Kuhl (1993) reports. Thus, the heightened activation of uncompleted scripts appears to be a general phenomenon with activities that are to be performed later. What the marginal specific contrast does signify to us is that unrelated components of a set of intended activities attenuates the effects that have been found before in this paradigm.

In examining Figure 1, it may appear that the independent manipulation of when the lexical decision task occurred (before vs. after performance) affected the neutral material more than it did the prospective material. As mentioned earlier in the introduction, the measurement of activation of the prospective script is a relative measure in a comparison with the neutral pair with which it was learned. Thus, when the lexical decision task has occurred before performance, the neutral pair appears inhibited. Likewise, when the lexical decision task comes after prospective script completion, the neutral script appears to be activated. What is being measured in the two pairs of bars in Figure 1 occurs at two different points in the experiment (and these were counterbalanced across participants to avoid practice effects in the aggregate measures). Therefore, the important point is that participants were instructed to treat the two blocks of the experiment independently and there were no latency differences when the assessment prior to or after completion occurred in the first versus second block of the experiment [both $t \mathrm{~s}(38)<1]$. Thus, as assumed in Anderson's (1983) $\mathrm{ACT}^{*}$ model, the activation of items in working memory

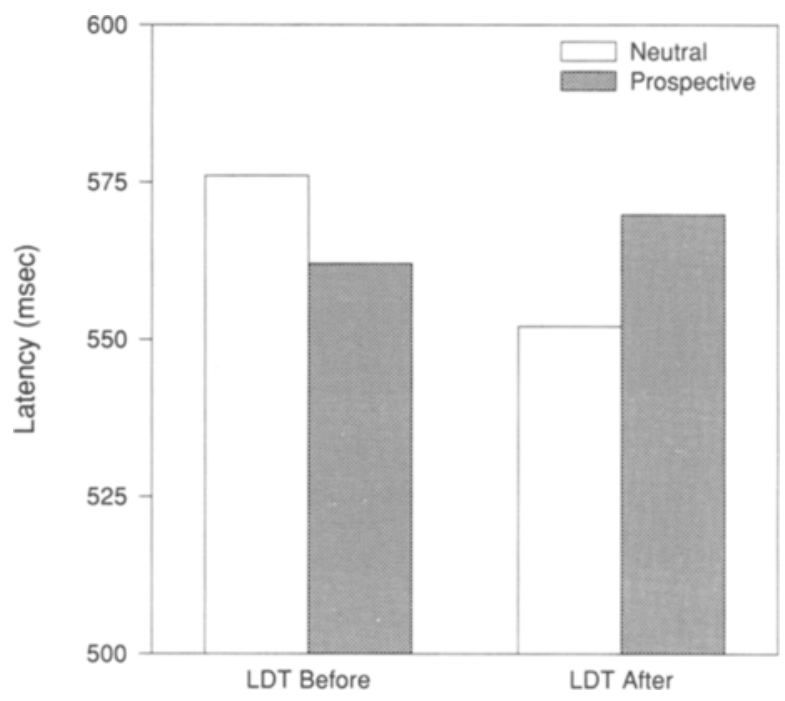

Figure 1. Latency to neutral and prospective scripts in Experiment 1 when the lexical decision task measurement of activation occurred before and after script performance. 
is distributed unevenly-in this case, distributed unevenly between the neutral and prospective material. If one assumes a constant amount of activation in working memory as portrayed in the $\mathrm{ACT}^{*}$ model, when the prospective material is in a heightened state of activation, the remaining contents of working memory are inhibited (left pair of bars in Figure 1). By contrast, when the prospective material is inhibited after completion, the neutral material is somewhat more activated (right pair of bars in Figure 1). Therefore, although differences in latency to the prospective material might not exist in the before versus after conditions $[t(39)<1]$, the overall activation of the neutral scripts can still differ $[t(39)=3.34]$. That difference, however, must be the result of what was manipulated: intentionality concerning the prospective script. We will return to this point in the General Discussion section. The important point is that intending to perform several unrelated activities that mimics real-world intentions to do several different things shows the same pattern of heightened activation prior to completion and the same inhibitory effect after completion as do semantically related script items.

\section{EXPERIMENT 2}

In Experiment 1, the heightened activation and inhibition associated with uncompleted and completed intentions, respectively, were replicated using scripts consisting of five unrelated components. Our goal in that experiment was to establish laboratory conditions that might resemble, in some sort of ecologically valid way, constellations of unrelated intentions that people might establish for themselves, such as things I want to do on my day off. Our motivation for conducting Experiment 2 was similar in that we wanted to examine what happened to the heightened activation of an intention after the intention was canceled. Marsh, Hicks, and Landau (1998) have shown that a large percentage (approximately $26 \%$ ) of everyday intentions get canceled or become impossible to fulfill for a variety of reasons. For example, meeting dates are broken because of emergencies, intentions to attend some entertainment activities are canceled because the allocated funds are needed for more mundane expenses, or inclement weather prevents attendance at some outdoor event. The fundamental questions addressed by this experiment were whether these canceled intentions (1) retain some of their heightened activation, (2) lose some of that activation and therefore resemble more the neutral contents of memory, or (3) become inhibited shortly after cancellation just as completed intentions appear to be. Any one of these three possibilities could have occurred, but our a priori prediction was that canceled intentions might resemble completed activities in terms of displaying inhibition. For this reason, we compared lexical decision latencies for a canceled prospective script and latencies taken after a script actually had been completed.

\section{Method}

Participants. Forty people who had not participated in Experiment 1 were recruited. They were awarded course credit toward fulfilling a research requirement. Three participants were replaced for failing to remember the correct sequence of actions to perform, and an additional participant was replaced because she displayed inordinately long reaction times.

Materials and Procedure. We used the four original scripts that Marsh, Hicks, and Bink (1998) used that had semantically related components (i.e., brewing coffee, setting a table, clearing a messy desk, and cleaning a computer). Our decision to do so was based on the somewhat attenuated effects found with the semantically unrelated components in Experiment 1. The procedural details were otherwise identical in most respects to those of Experiment 1 and our earlier study. The only difference was that in the first block of this experiment, we measured activation after the prospective instruction was delivered and after the prospective script had been performed. In the second block of the experiment, the experimenter canceled the script performance by saying something like "Uh, well, actually you cannot perform the script. I forgot to bring in some of the props for that script (pointing to the table with the props) so we will just go on with the remainder of the experiment." In fact, the experimenter had hidden several of the relevant props in a box prior to the participant's arrival. Our decision always to test activation after true script completion in the first block and to cancel the performance in the second block was guided by our belief that canceling the first performance might have led some participants to believe that the second performance would likewise be canceled. Such a belief might have caused some participants to fail to form an intention when told which of the two scripts they would have to perform in the second block. In all other respects this experiment was identical to Experiment 1 and those that came before in our laboratory.

\section{Results and Discussion}

Of the total number of trials, $4.5 \%$ were identified as errors, and an additional $1.1 \%$ were identified as outliers; both were excluded from the analyses. Pooling over the two lexical decision tasks, the bottom two rows of Table 1 set forth the overall latencies for the three classes of items tested. As can be seen in that table, the pattern of effects replicated that found in Experiment 1. Script words were responded to most quickly, followed by nonscript words, and latencies to nonwords were slowest. In a withinsubjects one factor ANOVA with three levels specifying the three classes of items, the mean latencies did differ $\left[F(2,78)=107.5, M S_{\mathrm{e}}=1,464.25\right]$. In specific contrasts, average latency was slower to nonscript words than to script items $[t(39)=9.92]$, and latency was faster to nonscript words than to nonwords $[t(39)=6.72]$. Under the assumption that faster latencies reflect heightened accessibility in memory, script items were the most activated.

Of these script items, latency to script words was a function of whether the items came from a prospective script or a neutral script. The results are set forth in Figure 2. As can be seen in that figure, canceling an intention had consequences that were similar to those of actually completing an intention. In both cases, activation in memory as measured by the lexical decision task showed that cancellation and completing an intention resulted in inhibition of the contents of the intention relative to more neu- 


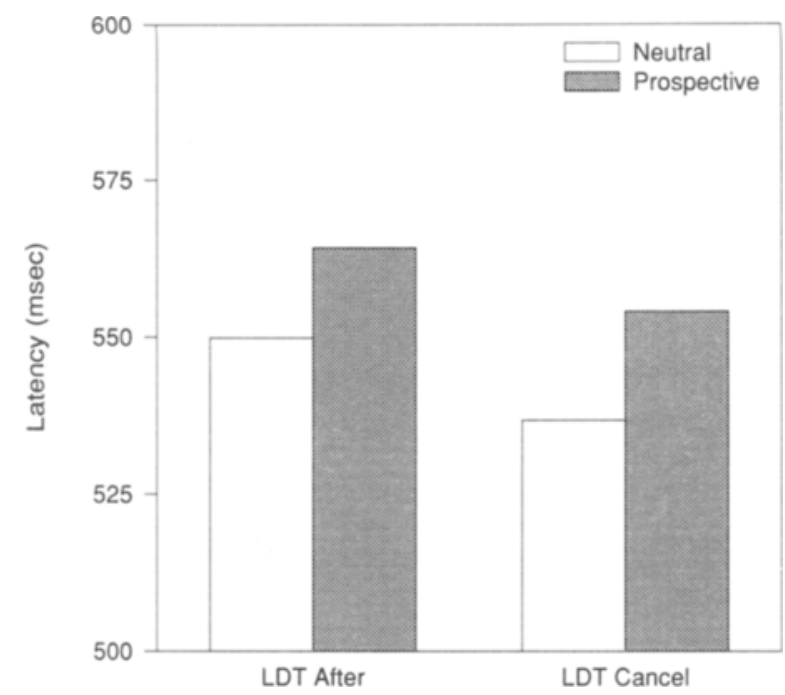

Figure 2. Latency to neutral and prospective scripts in Experiment 2 when the lexical decision task measurement of activation occurred after script performance and after cancellation of the intention.

tral material about which no intentionality had been formed. In a $2 \times 2$ ANOVA with the factors of type of script (prospective vs. neutral) and type of completion (canceled vs. completed), only the factor of type of script was statistically significant $\left[F(1,39)=13.30, M S_{\mathrm{e}}=\right.$ 760.31]. The type of completion and the interaction were not significant [both $\left.F_{\mathrm{S}}(1,39)<1\right]$. In terms of specific contrasts, latencies were slower to prospective scripts that had been completed as compared with their neutral mates $[t(39)=2.19]$. Likewise, latencies were slower to prospective scripts that were canceled as compared with their neutral mates $[t(39)=2.37]$. There were no latency differences between the two prospective scripts or the two neutral ones $[t \mathrm{~s}(39)<1]$. Therefore, both cancellation and completing a script resulted in some inhibition of the intention. Marsh, Hicks, and Bink (1998) replicated that inhibition effect associated with completion three times, and this experiment constitutes the fifth replication of that finding in addition to Experiment 1 herein. We turn now to a consideration of what theoretical and practical ramifications these results have for theories of prospective memory.

\section{GENERAL DISCUSSION}

In the intention superiority paradigm that we have used in these two experiments, when people are learning a pair of scripts they do not know which of the two they will have to perform later. Subsequent to our instruction, the intention to perform a set of actions appears to heighten the activation associated with the components of the tobe-performed script (Goschke \& Kuhl, 1993; Marsh, Hicks, \& Bink, 1998). By contrast, after the script has been performed, the activation seems to have subsided or even accrued inhibition (Marsh, Hicks, \& Bink, 1998). We have replicated both of these findings in this article. The fact that we have done so would be of little interest had we not also attempted to vary the conditions under which these two effects were obtained. Our goal was to use the intention superiority paradigm to ascertain whether more ecologically valid conditions that are known to occur in everyday prospective remembering would translate into differences in activation as measured by this laboratory paradigm. They did. In Experiment 1, a constellation of unrelated activities, mimicking the formation of the everyday intention to perform several unrelated activities, produced the standard heightened activation prior to performance and the inhibition effect after completion. In Experiment 2, we found that the fate of this heightened activation resulted in inhibition when participants were told that their required performance of the script had been canceled, just as inhibition appears to follow true completion of an intention. That manipulation was intended to mirror the common, everyday situation in which intentions become impossible to fulfill. After all, Marsh, Hicks, and Landau (1998) have demonstrated that almost one quarter of people's everyday intentions are overtly canceled or otherwise become impossible to complete.

When we speak of activation and inhibition, clearly the argument is a relative one in a comparison of the prospective script (completed, uncompleted, or canceled as tested in this article) and the neutral script that was paired with it. Therefore, the neutral script may appear to be inhibited when paired with a to-be-performed script that is more activated in comparison. Likewise, a neutral script may appear to be more activated than a prospective script that has either been completed or canceled. This pattern of effects is entirely consistent with Goschke and Kuhl's (1993) results, as well as their interpretation in terms of Anderson's (1983) ACT ${ }^{*}$ model of memory. Assuming that the amount of activation in working memory is fairly constant, measuring the activation of prospective memories and the more neutral contents of memories (i.e., latency to neutral script words in the lexical decision task) yields a relative measure of activation. In Anderson's (1983) model, the fixed and asymptotic "amount" of activation is assumed to be distributed unevenly among the concepts that are activated in working memory (p. 94). By this account, intentions that are yet to be performed have elevated amounts of activation relative to the neutral contents of memory, whereas completed intentions appear to possess less activation. Therefore, the intention superiority effect is composed not only of heightened activation to prospective memories but also inhibition effects of other elements in working memory. It is important that, as will be described momentarily, this pattern of results is exactly what would be predicted from theories of action control.

As Goschke and Kuhl (1993) originally pointed out, this interpretation is entirely consistent with equating uncompleted intentions to goal nodes in $\mathrm{ACT}^{*}$. Theoret- 
ically, these goal nodes are portrayed as receiving large and constant amounts of activation that do not need rehearsal in order to sustain their activation. Our own contributions in this area have been to extend this interpretation to why intentions should become inhibited after completion, and now in this article, after cancellation. In Anderson's (1983) model, goals that have been achieved are popped from the stack (i.e., removed), resulting in changes in focused attention (p. 33). Once popped, the associated activation undergoes rapid decay (p. 29). Whether that decay is simply that or rather is an active inhibitory process as we have portrayed it (cf. Norman \& Shallice, 1986) remains an open theoretical question. The important result is that uncompleted intentions as compared with intentions that are no longer relevant (through either completion or cancellation) display different patterns of activation relative to the more neutral contents of memory.

The activation and inhibition of intentions may have practical consequences for everyday prospective memory. For example, if these notions of activation and inhibition were reconceptualized as the revival rates of memory traces (e.g., Johnson, Kounios, \& Reeder, 1994; Marsh, Hicks, \& Bink, 1998), their practical value becomes immediately apparent. Heightened activation could reflect a faster revival rate upon reencountering the memory. A memory that is revived faster might allow for better eventbased prospective memory or even better time-based performance. Likewise, a completed (or canceled) intention might have a slower revival rate, which would be adaptive insofar as it is counterproductive to give a person the same message (i.e., an event-based task) more than once. Mäntylä (1996) speaks of "retrieval sensitivity" of prospective memories in much the same way as we are speaking of the revival rate of memories. When one finishes a task and cues oneself with "what next?" it would be adaptive if uncompleted tasks would come to mind more readily than those already accomplished. As Mäntylä (1996) notes, planning and monitoring will increase the retrieval sensitivity (i.e., revival rate) and thereby increase the probability that the prospective intentionality of a memory is realized and carried through to completion.

We offer the revival rate interpretation as an alternative conceptualization to activation and inhibition not because we believe it to be the "correct" theoretical interpretation, nor because it does any better job of explaining the phenomena being studied than does our appeal to ACT $^{*}$. Rather, we offer it because the account subsumes under one construct the two sides of one coin that are otherwise depicted as two rather separate constructs of activation and inhibition. The important point, however, is that to the extent that prospective memory is governed by theories of action control, the activation and inhibitory effects observed in these two experiments are entirely consistent with those theories. For example, in Norman and Shallice's (1986) model of central executive functioning, tasks are handled by the firing of action schemas (cf. Shallice \& Burgess, 1991). The firing of one schema causes lateral inhibition of other activated material, just as we found in Experiment 1. A similar process takes place in Anderson's (1983) ACT $^{*}$ theory. In both theories, the contents of working memory are matched to stored preexisting conditions that, once fired, guide behavioral responses. Thus, the lateral inhibition is consistent with our and Goschke and Kuhl's (1993) finding that the intention superiority effect is a consequence not only of the activation of prospective script words, but also of the resultant activation level of the neutral script with which it was paired.

Explicitly in Norman and Shallice's (1986) model and implicitly in Anderson's (1983) model is the underlying notion that central executive functioning is handled by condition-action schemas. Our intuition is that central executive functioning is critical to a variety of prospective memory tasks. For example, we have recently demonstrated that demands placed on the central executive as opposed to more peripheral articulatory and visuospatial systems greatly reduces event-based prospective memory performance (Marsh \& Hicks, 1998; see also Einstein, Smith, McDaniel, \& Shaw, 1997). In that same report, we found significant correlations between event-based performance and measures of central executive control (i.e., frontal lobe measures) such as verbal fluency and the Wisconsin Card Sorting Task. In addition, we have recently found that measures of attentional and memorial capacities distinguish people who use everyday memory aids from those who do not (Marsh, Hicks, \& Landau, 1998). Across two experiments, people who used diaries and daily planners had smaller attentional and memorial capacities than those who did not. We interpreted those results to indicate that people who use aids to remember everyday intentions do so as a compensatory strategy in order to accomplish as many intentions as do people who do not need such aids. There is even some neuropsychological evidence to suggest that the formation of an intention is a functionally different form of encoding, evidenced by additional frontal lobe activity (Shallice \& Burgess, 1991). Thus, a consistent pattern seems to be emerging from the literature on prospective memory, suggesting that intentions are special forms of memory that require central executive processes to be completed.

To return to the experiments that we conducted, our goal was to bring into the laboratory tasks and conditions that resembled some ecologically valid conditions under which prospective memory might be affected. In Experiment 1 , constellations of unrelated intentions were more activated prior to completion and were inhibited after completion. That situation resembles prospective intentions to perform several unrelated activities. Likewise, Experiment 2 demonstrated that cancellation of an intention resulted in deactivation of the intention just as was demonstrated for truly completed intentions. Together, these two experiments demonstrate the generality of this paradigm and its usefulness for investigating other similar ecologically valid questions concerning prospective memory. For example, if the item selection effects could be avoided, one question of interest would be whether 
self-chosen intentions would display a larger intention superiority effect than would intentions assigned by the experimenter from a pair of scripts. Because some intentions are externally imposed and others are established by oneself, they might differ in magnitude of activation. Another potentially interesting question is whether people's everyday intentions could in a lexical decision task be found to have heightened accessibility prior to completion and be inhibited or possess equal accessibility to neutral material after completion.

Although prospective memories are similar to other memories insofar as they are stored declaratively, they appear to be special in terms of the activation associated with them. That activation level appears to fluctuate as a function of the intention's status as completed, uncompleted, partially completed, or canceled. As researchers discover states of intentions other than the four or five that we have tested, it will be interesting to see how their activation levels fare in this laboratory paradigm, because the paradigm appears to be quite sensitive to analogues of situations that occur in everyday prospective memory.

\section{REFERENCES}

Anderson, J. R. (1983). The architecture of cognition. Cambridge, MA: Harvard University Press.

Butterfield, E. C. (1964). The interruption of tasks: Methodological factual, and theoretical issues. Psychological Bulletin, 62, 309-322.

Einstein, G. O., \& MCDaniel, M. A. (1990). Normal aging and prospective memory. Journal of Experimental Psychology: Learning, Memory, \& Cognition, 16, 717-726.

Einstein, G. O., \& MCDANiEl, M. A. (1996). Retrieval processes in prospective memory: Theoretical approaches and some new empirical findings. In M. Brandimonte, G. O. Einstein, \& M. A. McDanie (Eds.), Prospective memory: Theory and applications (pp. 115-141). Hillsdale, NJ: Erlbaum.

Einstein, G. O., McDaniel, M. A., Richardson, S. L., Guynn, M. J., \& CUNFER, A. R. (1995). Aging and prospective memory: Examining the influences of self-initiated retrieval processes. Journal of Experimental Psychology: Learning, Memory, \& Cognition, 21, 996-1007.

Einstein, G. O., Smith, R. E., McDaniel, M. A., \& Shaw, P. (1997) Aging and prospective memory: The influence of increased task demands at encoding and retrieval. Psychology \& Aging, 24, 479-488.

ELLIs, J. A. (1988). Memory for future intentions: Investigating pulses and steps. In M. M. Gruneberg, P. E. Morris, \& R. N. Sykes (Eds.), Practical aspects of memory: Current research and issues (Vol. 1, pp. 371-376). Chichester, U.K.: Wiley.

GosChKE, T., \& KUhL, J. (1993). Representation of intentions: Persisting activation in memory. Journal of Experimental Psychology: Learning, Memory, \& Cognition, 19, 1211-1226.

GoschKe, T., \& KUHL, J. (1996). Remembering what to do: Explicit and implicit memory for intentions. In M. Brandimonte, G. O. Einstein, \& M. A. McDaniel (Eds.), Prospective memory: Theory and applications (pp. 53-91). Hillsdale, $\mathrm{NJ}$ : Erlbaum.

HaRrIs, J. E., \& Wilkins, A. J. (1982). Remembering to do things: A theoretical framework and an illustrative experiment. Human Learning, 1, 123-136.

Johnson, M. K., Kounios, J., \& ReEder, J. A. (1994). Time-course studies of reality monitoring and recognition. Journal of Experimental Psychology: Learning, Memory, \& Cognition, 20, 1409-1419.
KVAVILASHVILI, L. (1987). Remembering intention as a distinct form of memory. British Journal of Psychology, 78, 507-518.

MÄNTYL ̈̈, T. (1993). Priming effects in prospective memory. Memory, 1, 203-218.

MÄNTYLÄ, T. (1996). Activating actions and interrupting intentions: Mechanisms of retrieval sensitization in prospective memory. In M. Brandimonte, G. O. Einstein, \& M. A. McDaniel (Eds.), Prospective memory: Theory and applications (pp. 93-113). Hillsdale, NJ: Erlbaum.

MARSH, R. L., \& HICKS, J. L. (1998). Event-based prospective memory and executive control of working memory. Journal of Experimental Psychology: Learning, Memory, \& Cognition, 24, 336-349.

Marsh, R. L., Hicks, J. L., \& BINK, M. L. (1998). The activation of completed, uncompleted, and partially completed intentions. Journal of Experimental Psychology: Learning, Memory, \& Cognition, 24, 350-361.

Marsh, R. L., Hicks, J. L., LandaU, J. D. (1998). An investigation of everyday prospective memory. Memory \& Cognition, 26, 633-643.

McDaniel, M. A., \& Einstein, G. O. (1993). The importance of cue familiarity and cue distinctiveness in prospective memory. Memory, $1,23-41$.

MEACHAM, J. A. (1988). Interpersonal relations and prospective remembering. In M. M. Gruneberg, P. E. Morris, \& R. N. Sykes (Eds.), Practical aspects of memory: Current research and issues (Vol. 1, pp. 354-359). Chichester, U.K.: Wiley.

NoRman, D. A., \& Shallice, T. (1986). Attention to action: Willed and automatic control of behavior. In R. J. Davidson, G. E. Schwartz, \& D. Shapiro (Eds.), Consciousness and self-regulation: Advances in research (Vol. 4, pp. 1-18). New York: Plenum.

RATCLIFF, R. (1993). Methods for dealing with reaction time outliers. Psychological Bulletin, 114, 510-532.

Ratcliff, R., \& MCKoon, G. (1978). Priming in item recognition: Evidence for the propositional structure of sentences. Journal of Verbal Learning \& Verbal Behavior, 17, 403-417.

Shallice, T., \& Burgess, P. (1991). Higher-order cognitive impairments and frontal lobe lesions in man. In H. S. Levin, H. M. Eisenberg, \& A. L. Benton (Eds.), Frontal lobe function and dysfunction (pp. 125-138). New York: Oxford University Press.

WILKINS, A. J., \& BADDELEY, A. D. (1978). Remembering to recall in everyday life: An approach to absent-mindedness. In M. M. Gruneberg, P. E. Morris, \& R. N. Sykes (Eds.), Practical aspects of memory (pp. 27-34). London: Academic Press

\section{NOTES}

1. All of the obvious counterarguments and artifactual accounts of the effect have been empirically tested and ruled out. For example, the effect is not one of selective rehearsal of the to-be-performed script. People asked to selectively rehearse both scripts and people engaged in a spatial interference task designed to prevent rehearsal nevertheless display the effect. Selective encoding is not the antecedent of the effect because the instruction is delivered post-learning. Moreover, the effect does not arise from the type of test that one is expecting, such as expecting to perform acts as a free recall test or expecting to watch someone else acts as a recognition test. See Goschke and Kuhl (1996, p. 64) for a synopsis of the empirical data against these counterarguments.

2. We entertained the idea of a "postponed" experimental condition. Unfortunately, such an experiment would be open justifiably to all of the criticisms about rehearsal that were discussed in note 1 . We do not consider this issue any further.

(Manuscript received July 25, 1997; revision accepted for publication March 15, 1998.) 